\title{
LAS REPRESENTACIONES SOCIALES DE LOS NIÑOS Y SU IMPACTO EN EL RESGUARDO DE SUS DERECHOS
}

\author{
SOCIAL REPRESENTATIONS OF CHILDREN AND ITS IMPACT \\ ON THE PROTECTION OF THEIR RIGHTS
}

María Consuelo Barletta Villarán ${ }^{1}$

\section{Resumen}

El presente estudio tiene como objetivo aproximarnos a las representaciones sociales que han estado vigentes el imaginario social en relación a quiénes son los niños y el rol que cumplen en la sociedad. Esto viene aparejado a la negación de sus derechos por quienes tienen la responsabilidad primera de velar por su resguardo, como son los miembros de su propia familia, mostrándose la dificultad de consolidar su visualización como sujeto de derechos en la sociedad peruana por venir arrastrando concepciones que culturalmente los invisibilizan y distorsionan el respeto a su dignidad.

Palabras clave: niños, adolescentes, representaciones sociales, derechos.

\begin{abstract}
:
The purpose of this paper is to approach the social representations present in the imaginary in relation to who children are and their role in society. This is coupled with their primary caregivers, such as family members, denying them their rights, thus proving how difficult it is to consolidate their position as legal subjects in Peruvian society, which continues to hold on to conceptions that make them culturally invisible and distort the respect to their dignity
\end{abstract}

Keywords children, adolescents, social representations, rights.

Profesora de la especialidad de Derecho de la Niñez y Adolescencia en la Facultad de Derecho de la PUCP. Asociada fundadora de la ONG COMETA. 


\section{INTRODUCCIÓN}

Iniciamos este estudio demostrando cómo históricamente se han recogido representaciones sociales de los niños evidenciadas en las prácticas sociales vigentes en los ámbitos en que éstos se desarrollan y desenvuelven.

Han sucedido situaciones de ausencia de instituciones para el resguardo de sus derechos al surgimiento progresivo (todavía vigente) de consolidar un sistema de protección garantista para ellos.

Asimismo, se puede constatar cómo la normativa ha reflejado un concepto del "menor" como sujeto incapaz, y que su pertenencia a un determinado estrato socioeconómico carente de control social informal forjaba en ellos la imagen de "peligrosidad".

Al tratarse de representaciones sociales culturalmente construidas estas se mantienen en el tiempo y son capaces de convivir con otras, reforzando percepciones equívocas que desencadenan en la trasgresión de derechos en los niños y adolescentes.

Actualmente, podemos constatar cómo estas representaciones sociales subsisten y cómo otras van apareciendo, demandando una agenda nacional que busque erradicarlas e ir posicionando la consolidación de condición de sujetos derechos (y también de deberes) de los niños y adolescentes en la sociedad peruana.

\section{CONTENIDO}

\subsection{Las representaciones sociales y los antecedentes históricos del surgimiento de una normativa especializada}

Las representaciones sociales de los niños y adolescentes debemos comprenderlas en la forma como hemos entendido a este sujeto social históricamente, a las características que les hemos atribuido y al rol que les hemos otorgado en el contexto social que les tocó vivir. En la medida que es un tema cultural, puede hacerse un seguimiento histórico y descubrimos como originalmente estos sujetos sociales han sido "invisibilizados" en su condición de sujetos con derechos en el devenir del tiempo.

Retrocediendo en el tiempo, durante la edad media la infancia no era visualizada como una etapa diferenciada a la adultez, en la escuela se compartían los mismos programas educativos con los adultos, no existía graduación de años escolares y por lo tanto, las aulas se caracterizaron por 
presencia de la extra edad (donde pocos alumnos, los privilegiados, eran encargados a sus maestros). El carácter colectivo según Philippe Ariès (1973) no dejo lugar a intimidades, y podemos agregar que tampoco permitió las individualidades; en ese sentido, el infante estuvo fuera del imaginario social. Sobre el particular, el autor en mención sostiene: "Sin duda alguna, eso significa que los hombres de los siglos X y XI no perdían el tiempo con la imagen de la infancia, la cual no tenía para ellos ningún interés, ni siquiera realidad." (p. 83)

Asimismo, el autor explica que la causa probable haya sido la percepción de que la infancia se constituía en una etapa de transición, la cual transcurría deprisa y la cual no dejaba "huella" en el individuo y con respecto a la cual, se perdía recuerdo, asimismo las altas tasas de mortandad infantil por enfermedades comunes en la infancia y las epidemias de la edad media, ocasionaron un desapego de la familia con respecto al infante.

Al estudiar Philippe Ariès las manifestaciones de arte pictográfico, evidenció que era a través de la iconografía religiosa, específicamente con la Virgen María como madre, que se comienza a representar al Niño Jesús como infante, esto sucede a partir de la segunda mitad del siglo XII.

Esto era una manifestación del pensamiento pre-moderno, en que todo tenía sentido en torno a la creación de Dios, el conocimiento era obtenido por la contemplación, no habiendo lugar al reconocimiento de las subjetividades o apreciaciones propias individuales, de esta manera la imagen del colectivo era lo que primaba, y no existía interés por atender las características propias de los individuos. Por otro lado, la actividad económica productiva que predominó en la sociedad medioeval fue la agrícola, en la cual se requería la solidaridad y el apoyo mutuo entre los individuos, todos en torno al objetivo económico común de la sobrevivencia a través del agro. Sobre el particular, Philip Aries ha señalado que el movimiento de la vida colectiva que se originó en la edad media, arrastraba en una misma oleada las edades y las condiciones.

Asimismo, según Ariès (1973) la presencia de los menores no se registraba fácilmente en la sensibilidad de los miembros de la sociedad, en la medida que el niño era considerado como un proyecto de persona adulta en el que predominaba la parte irracional. De esta manera, primó la necesidad de disciplinarlos de manera estricta y así desarrollar cuerpos adultos dóciles y subordinados, quienes guardaban las características de un buen ciudadano, miembro dúctil del orden social. (p.18-25) 
Es posteriormente con el Renacimiento, por el siglo $\mathrm{XV}$, que la modernidad coloca al ser humano como centro del pensamiento en el imaginario social, se respondió a la inquietud de cómo controlar a los infantes en la incipiente literatura sobre la infancia, enfatizándose en las prácticas de crianza y a suministrar consejos para la formación durante los primeros años de vida. Esto fue expresado en la obra "De Civilitate Morum Puerilium" de Erasmo de Rotterdam.

Una visión distinta del menor, tiene lugar en la literatura del siglo XV y XVI, con la obra anónima "El Lazarillo de Tormes y de sus fortunas y adversidades", que muestra a un niño travieso e ingenioso, ante la adversidad para sobrevivir, donde se busca resaltar lo gracioso o pintoresco de la infancia, lo cual es reflejado posteriormente en la pintura del Lazarillo (Murillo siglo XVII). Pero fue anteriormente, en el siglo XVI con el retrato del niño muerto (apareciendo como sombras detrás de sus hermanos), que se inicia una nueva etapa en la historia de las representaciones sociales de los infantes. Además se amplía el sentimiento de la infancia en las pinturas, con la imagen de un niño jugando y se van agregando otras infancias como de la Virgen María y Juan Bautista.

Por otro lado, durante el siglo XV y XVI se transcurre de la iconografía religiosa a la laica, representando costumbres y anécdotas, sin realizar una descripción exclusiva de la infancia, así también representaciones funerarias que tuvieron lugar durante el siglo XVI, primero en las tumbas de los profesores en donde aparece con sus alumnos, pero definitivamente es durante el siglo XVII, como plantea Philippe Ariès, que con la cristianización de las costumbres, se comienza a representar al niño con su familia, siendo éste el centro de la composición familiar, en la medida que existía la exigencia social de que la familia asumiera su rol de contensión y de transmisión moral a los menores.

Asimismo, Jacques Donzelot agrega un análisis del rol de la crianza de las nodrizas en el campo, lo que fuera parte de la costumbre del mundo premoderno, puesto que las mujeres de las ciudades se encontraban muy ocupadas, apoyando a sus esposos (artesanos o comerciantes), siendo otra razón, cuando eran muy ricas y querían despreocuparse de los afanes de la crianza.

Donzelot demuestra que gran parte de las nodrizas no suplieron la atención y cariño de una madre. Muy por el contrario, pareciera que utilizaban al niño como objeto de su revancha frente a sus patrones. Esto se debió a la falta de una remuneración justa y puntual. Asimismo, estas nodrizas 
favorecieron a la práctica social de la utilización de la "faja" (enrollando al niño con bandas), que tuvo como principal objetivo cortar la libertad del infante en sus movimientos, inmovilizándolos durante sus primeros tres meses. Cuestión que se mantuvo hasta el siglo XX.

Mientras que en el escaño más pobre se afianzaba la intervención de los hospicios, la práctica usual con respecto a los hijos naturales era abandonarlos en las puertas de las casas, de los conventos o iglesias, quedando a la intemperie fallecían por el abandono del que fueron destinatarios. En estos hospicios existían altas tasas de mortandad infantil, alegándose como causas, "... la dificultad de la administración para encontrarles nodrizas y a la mala voluntad e incompetencia de éstas." (Donzelot, s.f, p.1)

Finalmente, son la escuela y la familia en el siglo XVIII los espacios que propiciaron la salida del niño del mundo de los adultos propio en el medioevo, siendo un grupo de moralistas quienes exigieron a estas instituciones la formación moral y espiritual de los infantes. Así también, con la edad moderna se da la graduación en los años de estudios, correspondiendo a una edad para cada año.

De esta manera, los niños pasan de la libertad absoluta de la edad media a un control absoluto prodigado por la escuela, que utilizó como mecanismos privilegiados: el castigo corporal para la disciplina, siendo durante los siglos XVII y XVIII que tuvieron su auge los internados. En base a ello, García Méndez (1997) indica que "La historia de la infancia es la historia de su control"(p.1), puesto que transcurrieron de la indiferencia a la atención social para su represión y control, reafirmándolo Philippe Aries (1973) al agregar que:

"Se pasa de la indiferencia a un afecto obsesivo que dominó a la sociedad a partir del siglo XVIII (...) cuando la familia acaba de reorganizarse en torno al niño y levantaba entre ella y la sociedad el muro de la vida privada (...) Dicha familia corresponde a la necesidad de intimidad y también de identidad, pues los miembros de la familia se reúnen por sus sentimientos, sus costumbres y el tipo de vida..." (p.27)

Este es el origen de la institución familiar como la hemos conocido por mucho tiempo, sin ningún tipo de interferencia por agentes externos, permitiendo que detrás de sus muros se cometan las peores trasgresiones a los derechos fundamentales de los niños. Asimismo, el siglo XVIII se caracteriza por una atención especial a la conservación de los hijos. Sobre el particular, Donzelot indica que ello: "...va a significar (...) obligar a que eduquen a 
sus hijos todos aquellos individuos que tienen tendencia a abandonarlos al cuidado del Estado o a la mortífera industria de las nodrizas." (p.3)

En base a ello, a mediados del siglo XVIII se inicia la instauración de tornos en los hospicios para salvar la vida de los recién nacidos que eran abandonados en las calles, generalizándose en 1811 tal y como lo indica Donzelot, para posteriormente entrar en decadencia o desaparición, siendo el último implementado en el año de 1880, cumpliendo durante ese tiempo, la función de conservar la vida de los llamados "niños expósitos" y de cuidar el honor de las familias. Los tornos eran estructuras de madera giratorias que se colaron en instituciones religiosas encargadas de los hospicios y que permitían resguardar la identidad de los sujetos autores del abandono, de esta manera se dejaba al recién nacido y se giraba la estructura, logrando que a los pocos minutos el infante quedara en los brazos del encargado en la institución. En la actualidad, todavía encontramos estas estructuras en los claustros de religiosas, cumpliendo otra finalidad.

Sin embargo, su decadencia se debió primordialmente a la relajación de deberes de los padres, al percatarse que el Estado podía asumir su responsabilidad, haciéndose cargo de sus hijos, sobre el particular resulta ilustrativo lo indicado por Donzelot:"...no sólo las familias legítimas abandonan a sus hijos a causa de su extrema pobreza, sino que algunas que podrían criarlos también pretenden que el Estado los alimente." (p.5)

De esta manera, los tornos favorecieron al rol asistencialista de las instituciones religiosas, lo que terminó desbordando su función. En base a ello, se denunció que el sistema del torno secreto originó funestos resultados y contribuyó, en algunos países, como en Francia (1858), al aumento considerable de los expósitos. En Argentina, el torno de la Sociedad de Beneficiencia, se cerró en abril de 1891, creándose en su reemplazo una oficina de recepción bajo la garantía del secreto. De esta manera, según Bullrich (1919) distinta fue la suerte de los huérfanos en relación a los abandonados moral y materialmente por sus familias, los primeros contaron con asistencia privada, mientras que los segundos con el apoyo de instituciones públicas, asumieron un rol de contención a los sujetos que tenían tendencia natural o socialmente adquirida a la conducta antisocial.

Es así como el siglo XVIII trajo consigo sus propios cuestionamientos a las prácticas o costumbres imperantes al interior de las familias, resaltándose en los discursos la importancia de la lactancia materna, como también sobre la elección de las nodrizas y, por otro lado, se denuncia incansablemente la práctica del fajamiento de los bebes y el uso del corsé en la mujer, por el 
debilitamiento que le producía en su futuro rol como madre. Por otro lado, se planteó mayor exigencia a la familia y a la escuela, a fin que estas instituciones lograran contener a los niños replegando su naturaleza humana plegada de maldad por el pecado original de los primeros padres.

De esta manera, estas instituciones ejercieron sobre los niños el castigo físico, que fuera tolerado y aceptado socialmente. Finalizando el siglo XIX, fue conocido un caso que encontró gran eco en la prensa y opinión pública en la sociedad estadounidense, se trataba de la niña Mary Ellen Wilson (1864-1956) de 10 años de edad, quien fue sustraída a sus padres adoptivos por las autoridades judiciales, rompiendo con la visualización de los asuntos familiares como un tema de interés privado para constituirse en asunto público. Según la investigación, a Mary Ellen le clavaban tijeras y la ataban para castigarla, asimismo se indicó que la niña era hija biológica de Francis y Thomas Wilson, su padre fue asesinado en la batalla de Cold Harbor, Virginia en 1864, el mismo año que Mary Ellen nació. Los efectos de la post guerra llevaron a que su madre, viuda joven sin medios para cuidar a su hija, la entregara a Mary Score, una persona acomodada económicamente. La niña es visitada inicialmente pero posteriormente su madre deja de hacerlo, motivo por el cual, Mary Score la entrega a los servicios sociales, posteriormente Mary Ellen es promovida en adopción a Mary y Thomas McCormack.

En el expediente de adopción se indica que Thomas McCormack sostiene que Mary Ellen era su hija biológica, siendo la realidad que éste había perdido a sus hijos biológicos por enfermedades infantiles. De esta manera, obtuvo que el orfanato se la entregara de manera pronta. Lamentablemente, Mary Ellen vuelve a tener una pérdida, su padre adoptivo fallece y Mary McCornack contrae nupcias con Francis Connolly

Fue Mary Smitt quien puso en conocimiento de la trabajadora social Etta Angell Wheeler, que todos los días escuchaba gritos de una niña, "que le rompían los oídos", no teniendo forma de confirmar que existiera una niña al otro lado de la pared, puesto que nunca vio salir a sus vecinos acompañados de alguna niña.

Ante esta denuncia la trabajadora social ingresa al domicilio de los Connolly, describiendo posteriormente la escena en estos términos: "Era un despojo más que una niña, su cuerpecito era esquelético y muy bajo para su edad, Mary Ellen tenía síntomas de desnutrición y abandono. Estaba sucia, vestida con ropas raídas y mugrientas, aunque intentase tapar sus cicatrices, se las veía por su cara, brazos y piernas, algunas producidas con las tijeras de 
su madre". La trabajadora social, la vio cumpliendo una faena doméstica, al encargarse de lavar los trastes que estaban en lavadero; asimismo, encontró sobre la mesa un pesado látigo de cuero rígido.

En la investigación, se recogieron frases significativas de la niña que evidenciaron el infierno que vivió: "Nunca me ha besado nadie, mamá tampoco"; "nunca me han acariciado"; "nunca he hablado con nadie más que con mis padres adoptivos, porque si intentaba hacerlo me azotaban con el látigo"; "no sé por qué mi mamá me pega con el látigo, la verdad es que nunca me dice nada mientras lo hace"; "yo no quiero volver a vivir con ella, porque me hace daño"; "nunca he salido de casa en mi vida". ${ }^{2}$

A este descubrimiento inhumano, para la trabajadora social se sumó la situación indignante de no encontrar juzgados que asumieran el caso de Mary Ellen puesto que se consideraba que lo sucedido en el hogar era estrictamente de carácter privado. La institución que activó el caso fue la "Sociedad para la Protección de los Animales" de Nueva York, los argumentos esgrimidos fueron sencillos pero finalmente eficaces, Mary Ellen era parte del reino animal, debía aplicarse a su favor la Ley contra la Crueldad hacia los animales, que estaba vigente por la efectiva e intensa labor de la sociedad citada. Posteriormente, este hecho coincide con la creación de la "New York Society for the Prevention of Cruelty to Children". De esta manera, fue en el año 1874, que se dictó la primera sentencia en la historia condenando a padres maltratadores. ${ }^{3}$ La madre adoptiva fue arrestada y acusada de maltrato hacia su hija.

Lo que evidencia este caso es la total invisibilidad del maltrato de los niños en el ámbito familiar en la época de Mary Ellen, puesto que no existían leyes ni tampoco juzgados. Este caso fue altamente aleccionador porque nos muestra la invisibilidad social que tuvo lugar de los derechos de los niños al interior de la familia con la relación parental y cómo se dio origen a movimientos sociales a favor del resguardo y defensa de los mismos.

Asimismo, la escasa valoración social y jurídica del menor proveniente de estratos socioeconómicos pobres se hizo manifiesta con su equiparación al delincuente adulto, cuando este menor estuviera en "situación irregular"; esto ocasionó que surgiera un movimiento social llamado los "Reformadores", en Europa a fines del siglo XIX, cuyos integrantes abogaron por un tratamiento penal diferenciado para los menores que infringiesen la ley o se encontraran en "situación irregular", impulsando acciones para la separación de los

Ver: http:/ / acubastos.blogspot.com/2006/01/la-historia-de-mary-ellen.html
Ver: http:/ / territoriocat.wordpress.com/2010/10/22/la-historia-de-mary-ellen/ 
menores de las cárceles de los adultos. Esto había tenido lugar, por la falta de instituciones especializadas para brindar un tratamiento a los menores en "situación irregular", siendo una manifestación histórica adicional de la invisibilización sociojurídica del menor. Sobre el particular, la jurista venezolana Georgina Morales (2001) con su amplia experiencia en el ámbito judicial, sostiene:

"Desde los remotos orígenes del derecho y hasta los inicios del siglo XIX desde el punto de vista punitivo, no se distinguió si los delitos eran cometidos por niños, jóvenes o adultos (...). En términos generales se fijaba la edad de los nueve años como límite de la inimputabilidad absoluta, adoptándose para los mayores de esa edad, los criterios del discernimiento (...). A lo sumo, los códigos penales de la época, reducian las penas en un tercio cuando los autores de los delitos tenían edades inferiores a los dieciocho años." (p.2)

Coincidiendo con esta apreciación jurídica, el argentino Eduardo Bullrich (1919) denuncia que durante la primera década del siglo XX, los menores que fueron detenidos por diversidad de supuestos que aludían a abandono y a una supuesta ausencia de control social, como por ejemplo: vagancia, mendicidad $u$ otras contravenciones pequeñas, y hasta faltas de respeto a los tutores, eran recluidos en total hacinamiento con los adultos, en la más terrible promiscuidad, y recibían lecciones para actuar como delincuentes. "Las cosas más repugnantes se ven y se sienten vivir entre esas paredes húmedas y en esa atmósfera de vicio burdo y precoz... "(p.119) ; además del contagio de enfermedades venéreas y otras lacras en los menores en situación irregular (p.94). En relación al tema, este jurista expresa la gravedad de la situación, en estos términos: “...el bueno sale pervertido y el pervertido se convierte en vicioso o anormal" (119).

Es necesario indicar que estas denuncias fueron planteadas en la Conferencia del Niño Peruano en 1922, evidenciando que esta realidad sucedió a nivel internacional.

\subsection{Surgimiento de la normativa especializada: La Doctrina de la Situación Irregular.}

Al requerirse retirar al menor en situación irregular del mundo jurídico de los adultos y apartarlos de las cárceles en que eran recluidos, se creó un sistema especializado para ellos, en que su condición de incapaz e inimputable fue lo fundamental para diferenciar su tratamiento jurídico. 
Las legislaciones de menores que fueron la expresión normativa de la Doctrina de la Situación Irregular a finales del siglo XIX en Europa e inicios del siglo XX en América, consistió en la consolidación de un sistema sociojurídico organizado para prodigar un control sociopenal encubierto en los llamados "menores en situación irregular".

La manifestación de la representación social del "menor en situación irregular" como un "sujeto peligroso" o "potencialmente peligroso" para el orden social o la seguridad ciudadana, permitió establecer un sistema jurídico cuya principal estrategia de intervención fue la priorización del albergamiento de estos menores en centros de corrección bajo un aparente discurso de protección que encubrió finalmente una manifestación de control social. En consecuencia, las características de la Doctrina de la Situación Irregular pueden sintetizarse en el control perverso que tuvo lugar bajo un discurso de protección de un sector de la infancia, aquel que supuestamente devenía en peligroso para el orden social.

El tratamiento normativo de los menores en situación irregular en el Perú, tiene sus inicios en el Título XVIII del Código Penal de 1924, brindándosele una sección especial dentro de un Código de adultos, lo que significó un avance en el tratamiento normativo puesto que previamente no existió una mirada diferenciada a los menores en situación irregular, formalmente establecida. Podemos afirmar entonces que este tratamiento normativo dio origen a la especialidad del derecho de menores.

Sobre el particular, al presentarse el anteproyecto del Código de Menores de 1933, el doctor Ildefonso Ballón (1935), autor del mismo, mencionó que: "Derecho Penal moderno, puede legítimamente considerarse como antecesor y casi generador del Derecho de Menores..., se ha llegado a procurar su solución dentro de los principios de la defensa social del Derecho..." Por dicha razón, Emilio García Méndez (s.f), agrega sobre el particular, que:"Sin duda, el origen de la especificidad jurídica de la infancia es de naturaleza estrictamente penal" (p.17), pero al surgir dentro del ámbito penal de adultos, estuvo influido por las corrientes doctrinales de la época, entre las cuales tiene mayor relevancia el positivismo criminológico, que imbuido de las teorías de la Defensa Social y Peligrosista impactaron en el tratamiento legal de los menores en "situación irregular".

Su principal sustento estuvo en que "el hombre no goza de absoluta libertad y que sus actos están determinados por diversos factores endógenos y exógenos que operan sobre ellos y que son capaces de guiar la mano que roba o que mata. (Castillo, 1968, p.37) “ De esta manera la teoría de la Defensa 
Social planteó el requerimiento de identificar los sujetos considerados como "peligrosos" o "potencialmente peligrosos" para el orden social, y el delito o acto antisocial fue concebido como un síntoma de esta "peligrosidad"; en consecuencia, los menores debían ser protegidos de sí mismos y de su entorno sociofamiliar, puesto que eran actos "incontrolables por ellos mismos" (Castillo, 1968, p. 29).

En el marco de los hechos que marcaron la vigencia de la Doctrina de la Situación Irregular, encontramos el caso Gault en los Estados Unidos. Un adolescente de 15 años llamado Gerry Gault fue acusado de hacer unas llamadas indecentes a una vecina en el verano de 1964, y fue parte de una investigación en la que no se le informó de ningún derecho, sus padres no fueron avisados por la policía de su detención, así también se produjeron otras trasgresiones de garantías (lo que fue justificado en la aplicación de las legislaciones de menores de la doctrina de la situación irregular en el sistema estadounidense), tal como su internación en un establecimiento correccional de Arizona hasta los 21 años de edad, mientras que un adulto por los mismos hechos podría haber sido condenado a una multa de 50 dólares o a dos meses de prisión.

Resulta sobre el caso, interesante lo escrito por el juez Fortas "Under our Constitution, the condition of being a boy does not justify a kangaroo court" que traducido al español significa: "El derecho del Estado, como parens patriae, a negar al niño derechos procesales", de esta manera se argumentó que un niño a diferencia de un adulto "no tiene derecho a la libertad sino a la custodia"; en ese sentido, si sus padres fallan en realizar de forma efectiva sus funciones custodiales, el niño es "delincuente" y el Estado puede intervenir. Al hacerlo no le priva de sus derechos, porque este no los tiene, solo le proporciona la custodia que le corresponde. De esta manera, estos procesos fueron descritos como civiles más no como criminales.

Entre las características de las legislaciones de menores que impactaron en la construcción de la Doctrina de la Situación Irregular, podemos mencionar:

1. Los menores fueron considerados inimputables ${ }^{4}$, equiparándoseles a tipos anormales.

Se habló del menor como inimputable porque se afirmaba que carecía de la madurez necesaria para darse cuenta de la repercusión de su actuar; es decir, del daño personal y social producido. Esto nos lleva al campo

La inimputabilidad no significa que no se le aplicará el poder coactivo estatal sino que no le aplicarán las reglas de los adultos, no siendo en consecuencia justificable el otorgamiento de garantías procesales. 
subjetivo, en la medida que la inimputabilidad proviene de un elemento biológico, la edad, la enfermedad mental, la idiotez, o también cuando se dan las deficiencias psicosocioculturales, estando la persona incapacitada de evaluar la norma que le impone una cultura y la sociedad.

La visión del menor, en términos generales, fue como un sujeto pasivo de las acciones estatales, no importando o siendo irrelevante su opinión o participación para definir las medidas que le fueran aplicables.

\section{Valoración del Derecho Penal de autor}

Para determinar la medida aplicable al caso, fueron examinadas las circunstancias personales, familiares y sociales de los menores, promoviéndose de esta manera un derecho penal de autor, se evaluaba las características "peligrosistas" y no los hechos cometidos por los menores, de esta manera lo sustancial no era lo que "hubiera hecho" sino "lo que pudiera hacer a futuro".

Es así como la ausencia o disfuncionalidad de la familia, así como la deserción escolar, evidencian la inexistencia de un control social informal, que hacen del menor un "sujeto peligroso", siendo éste el primer síntoma de su "situación irregular" y de su conducta predestinada a la infracción a la ley penal. Sobre el particular, Georgina Morales (2001) señala que la situación irregular de los menores no eran visualizados como trasgresión de derechos sino más bien en el reconocimiento que "...la intervención debía ocurrir al darse los primeros síntomas que fatalmente determinarían a que esos niños o jóvenes llegarán a la delincuencia." (p.27)

\section{Categorías Jurídicas imprecisas para justificar la intervención estatal.}

La influencia de la Teoría de la Defensa Social como finalidad de la intervención penal del Estado, favoreció a la creación de categorías jurídicas imprecisas o lo suficientemente genéricas para permitir la intervención estatal en el ámbito familiar sin mayores restricciones; en esa medida, se justificaron intervenciones en poblaciones de menores con diversos perfiles, cuya principal coincidencia estuvo en la carencia o falta de control familiar.

En consecuencia, al malhechor, delincuente y criminal hay que protegerlo para sacarlo de la situación de inferioridad que vive y que genera su situación de "peligrosidad".

De esta manera, con las legislaciones de menores se buscó crear categorías jurídicas para justificar la intervención del juez en el ámbito 
privado y familiar del menor, recalcando circunstancias que enfatizaban sus carencias, problemas y necesidades. De esta manera, la mayoría de la doctrina coincide en esta clasificación: como menores abandonados, menores en peligro moral, menores en peligro material. ${ }^{5}$ Es así como, las legislaciones de menores permitieron contar con supuestos de situación irregular irrestrictos o no taxativos en que "Las categorías abiertas finales permiten cualquier intervención de un menor por parte del brazo protector del Estado y en nombre de su interés". ${ }^{6}$

\section{Justicia Especializada para los menores en situación irregular.}

El primer tribunal de menores fue en Illinois en el año 1899, originando una Corte Juvenil diferente a la Corte Criminal para Adultos. En la legislación peruana, fue el Juzgado de Menores contemplado en el artículo 410 del Código Penal de 1924. Sobre el particular, Delia Mateo de Ferrini (2000) señala que: “...la idea de sustraer al menor del derecho penal y de la jurisdicción penal ordinaria, motivó inicialmente la creación de una jurisdicción especializada"(p.5), y originó su inclusión posterior en el Código de Menores de 1962.

Las principales características de la justicia especializada de los menores, son:

a. Competencia: El juez de menores resuelve sobre causas relacionadas al abandono o peligro moral y también sobre casos de los menores de 18 años que hayan cometido hechos contrarios a la ley, habiendo configurado delitos o faltas. ${ }^{7}$

b. Facultades: El juez de menores tiene amplias facultades con libre discrecionalidad para disponer la medida que correspondiera al caso concreto. En tal sentido, señala García Méndezn (1997) que: “Ungido de una competencia omnímoda penal-tutelar, el juez de menores resulta ser el encargado de resolver paternalmente, las deficiencias estructurales del sistema." (p.18)

c. Garantías: El juez de menores actuaba siempre en beneficio del menor (brindando protección); por ello, no correspondía otorgar garantías que eran propias de los procesos donde se discutía alguna controversia jurídica y en que había que poner límites al rol persecutor del Estado.

Definiciones recogidas del vocabulario multilingüe, polivalente y razonado de la terminología usual en protección de menores, elaborado por Rafael Sajón, José Achard y Ubaldino Calvento para el Instituto Interamericano del Niño. Ibid p. 36.

Artículo 64 del Código de Menores. 
Según Bustos Ramírez (2004, p. 536), no hay publicidad, no hay abogado defensor, en la medida que se trataba de un proceso no contradictorio; es decir, no había nada que contradecir. La finalidad era brindar protección al menor sin requerir formalismos procesales.

d. No claridad en la finalidad del proceso: Límites difusos entre la reacción punitiva y la reacción tutelar, tal y como lo indica Miguel Cillero al sostener que:

"En el plano teórico es posible reconocer dos formas de reacción o "control" sobre el delito juvenil: la reacción punitiva y la tutelar. En la práctica, estas dos dimensiones de la reacción social se superponen y la actuación de la sociedad se ve influida tanto por la una como la otra, ya que se trata de dos componentes comunes de un conflicto social único: la protección conjunta del desarrollo integral de los niños y jóvenes y la defensa de bienes jurídicos considerados esenciales para la convivencia humana" ( $p .78)$

De esta manera, el abandono y la delincuencia juvenil eran "dos caras de la misma moneda"; es decir, eran dos problemas sociales intrínsecamente relacionados.

e. El internamiento como la medida privilegiada: Con los menores en situación irregular se priorizó la medida de protección de internamiento. Sobre el particular, Juan Bustos Ramírez (1992) sostiene que "la finalidad que se pretenda perseguir no cambia la naturaleza ni de la privación de libertad ni de las medidas de seguridad, ambas siguen teniendo una naturaleza coactiva y de restricción de derechos (...). Las penas y las medidas de seguridad son derecho penal."(p. 174)

Cuando se les aplicaba una medida de protección la consecuencia o impacto final en la vida de los "menores en situación irregular" fue la restricción de libertad, motivo por el cual, se dio un "fraude de etiquetas" como alude el mismo autor, puesto que una aparente protección encubría una estrategia de control sociopenal a este sector de la infancia.

De esta manera, las normas eran aplicadas a los supuestos tutelares y penales, ventilados en los mismos juzgados de menores y por lo tanto, no importaba el perfil de los menores en situación irregular estos eran alojados en los mismos centros correccionales. Esta intervención se destinó más a "... solucionar el problema social que significaban los menores en la calle que a proteger al menor a la situación social que lo exponía a los peligros de la calle."(Mateo, 2000, p. 65) 
A fin que estas leyes cumplieran con su finalidad, se estableció la institucionalización o la reclusión en alberges como la medida privilegiada. De esta manera, se reprimía en los menores su tendencia natural (genética y heredada) a la criminalidad y de su entorno sociofamiliar desfavorable para su inserción social. Sobre el particular, resulta sumamente importante visualizar el impacto de esta estrategia de intervención social en el ámbito civil, que refiere a la patria potestad prevista en el numeral 3 del artículo 423 del Código Civil, el cual señala:

"Son deberes y derechos de los padres que ejercen la patria potestad: 3. Corregir moderadamente a los hijos $y$, cuando esto no bastare, recurrir a la autoridad judicial solicitando su internamiento en un establecimiento dedicado a la reeducación de menores."

Así, el internamiento fue concebido como un tratamiento especializado para el "menor en situación irregular", y la duración de la medida era indeterminada. Al respecto, se señalaba que "...sólo una sentencia de carácter indeterminado podrá convertir a la protección en un hecho permanente."(García, s.f. , p. 164) En relación al tema, Georgina Morales (2001) agrega que:

"La duración de las medidas reeducativas al estar inspiradas en la noción de tratamiento individual no está determinada; el tratamiento reeducativo, al igual que en las enfermedades patológicas, terminará cuando haya desaparecido el mal. El lapso de la medida es totalmente indeterminado y dependerá de los resultados obtenidos en el tratamiento educativo aplicado" (p.19) Además la autora indica que: " el parámetro para su duración lo establecerá la conducta del menor durante el tratamiento." (p. 44)

La finalidad última de estos juzgados de menores es descrita por Federico Palomba (1995) al indicar que: "La creación de la justicia especializada de menores; la expedición de leyes, la creación de tribunales y servicios especializados para los menores de edad, es el resultado de un movimiento humanitario que pretende liberar a los niños del sistema penal."(p. 1)

Finalmente, según Emilio García Méndez “Con relación a la doctrina de la situación irregular, no significa otra cosa que legitimar una potencial acción judicial indiscriminada sobre aquellos niños y adolescentes en situación de dificultad"(p.22). En consecuencia, según lo señalado, se creó un sistema de control para estos menores cuya atención no estuvo en su situación de abandono sino en su condición de peligrosidad para la sociedad. 
El lamentable impacto fue la aplicación de medidas asistencialistas sin límites temporales, manteniéndose a los menores en situación irregular recluidos en centros de readaptación, padeciendo las limitaciones del encierro, privándoseles de la posibilidad de crecer y desarrollarse en un entorno sociofamiliar. En resumidas cuentas, los efectos de la aplicación de las legislaciones de menores ocasionaron lo siguiente: 1. Estigmatización del menor, dependiente del Estado, no ser autónomo, sino dependiente e incapaz, contraviniendo el resguardo de su derecho a la dignidad. 2. Produjo un fraude de etiquetas, medidas que implican restricción de derechos; su finalidad no cambia su naturaleza coactiva y penal.

\subsection{La visión jurídica del niño como sujeto de derechos y representaciones sociales vigentes.}

Con la ratificación de la Convención sobre los Derechos del Niño ${ }^{8}$ se inicia una nueva etapa en la exigibilidad de los derechos de los niños en la sociedad peruana. Esta normativa internacional con efecto vinculante y rango constitucional para el sistema normativo peruano, otorga un nuevo status al niño en el ámbito social y jurídico, buscando que sea visualizado como un sujeto con derechos, deberes y obligaciones, cuyo ejercicio y exigibilidad es progresiva conforme a su edad y madurez. Sin embargo, podemos evidenciar la vigencia paralela de representaciones sociales, que o bstruyen el resguardo de esta condición jurídicamente atribuida.

\subsection{La invisibilidad del niño en el momento actual}

Como podemos identificar la invisibilidad del niño en el imaginario social ha originado el surgimiento de diversas representaciones de la niñez y adolescencia, las cuales se han manifestado históricamente y aún en la actualidad, en el contexto social peruano. Sin ánimos de agotarlas ni mucho menos de mostrar la explanada de todas sus expresiones, procedemos a mostrar algunos fenómenos sociales que evidencian la trasgresión de los derechos de los niños y adolescentes.

Asimismo, es importante reconocer previamente la simultaneidad de las representaciones sociales, que evidencian la complejidad de las problemáticas analizadas. Autores como Rosario Panez ${ }^{9}$, han logrado mostrar la existencia de representacionessociales, quehan tenidosu surgimientoen un momentohistórico y se han mantenido en el tiempo, aludiendo por ejemplo, a representaciones que tuvieron su manifestación prioritaria en los siguientes contextos: el niño como

Ratificación mediante Resolución Legislativa №25278, de fecha 03 de agosto de 1990.

Ver Panez, Rosario (1989) Bajo el Sol de la Infancia: creencias y tradiciones en la crianza limeña. Lima : CONCYTEC 
"adulto pequeño" (Grecia y Europa siglos XVI y XVIII), el niño como "ser malo" (Europa siglo XVIII), el niño como "tabula rasa" ( Europa siglo XVII y XVIII), el niño como "estorbo" (Europa siglo XVIII), el niño como "recurso Económico" (Inglaterra siglo XVII) y el niño como "propiedad" (en todas las sociedad donde los derechos de los niños no se cumplen).

Como una manifestación de la invisibilidad del niño o una mirada peyorativa hacia ellos podemos mencionar determinados hechos históricos actuales o recientes como por ejemplo, lo sucedido en la época del conflicto con grupos subversivos en el Estado peruano. Sobre el particular, el Informe de la Comisión de la Verdad y Reconciliación recuenta como desde comienzos de la década de los ochenta, el Grupo Terrorista "Sendero Luminoso" asesinó a niños por los siguientes motivos: 1 . Ser parte de las masacres cometidas contra las comunidades; 2 . Ser concebidos como carga al momento de sus desplazamientos; 3. Someterlos a condiciones extremas de desnutrición; 4. Temor a que los delataran si eran rescatados por el ejército 5. Que se vengaran cuando crecieran. En consecuencia, a los jefes de la organización terrorista se les atribuye el $50 \%$ de las muertes producidas a los niños, niñas y adolescentes. ${ }^{10}$

Así también, los niños y adolescentes fueron víctimas de tortura, tratos crueles, inhumanos y degradantes. Esto sucedió prioritariamente en los departamentos de Ayacucho, Cusco, Apurímac, Huancavelica y Huánuco, durante los años 1983 -1984 y 1989 - 1992, prácticas que en ocasiones consistieron en cortar orejas o mutilar manos como "castigo ejemplificante."

\subsection{El niño como adulto en pequeño}

Esta representación social no permite reconocer en los niños y adolescentes la etapa de desarrollo humano que viven, exigiéndoles roles y responsabilidades que no competen a su edad. De esta manera, se afecta al proceso de desarrollo normal de los niños y adolescentes, cuestión no tolerada con la normativa actual de la especialidad.

Sucesos como los acontecidos en las escuelas populares de Sendero Luminoso en el Valle de Apurimac y Ene (VRAE) ${ }^{11}$, en donde los niños son adoctrinados en tácticas militares y uso de armas, con el consentimiento de sus propios padres, acontecimiento revelado en los primeros meses del año

\footnotetext{
10 Ver:http://www.usip.org/sites/default/files/file/resources/collections/commissions/Peru01-Report/Peru01-Report_Vol8.pdf

11 Ver: http://www.inforegion.pe/49653/sendero-luminoso-estaria-formando-nuevos-comites-populares-en-ayacucho-y-el-vrae/
} 
2010, nos permiten verificar que estos niños y adolescentes no sólo fueron invisibilizados sino tratados como adultos, transgrediéndose su derecho a la integridad, desarrollo integral, pero sobretodo la protección específica que les corresponde por ser niños o adolescentes. ${ }^{12}$

Otra manifestación de esta representación es encargar a los niños o adolescentes asumir responsabilidades que no les corresponden por su edad, como por ejemplo: hacerse cargo del cuidado y atención de otro niño. Los padres son los responsables de velar por el cuidado y atención de sus hijos, rol que se puede delegar en otro adulto pero nunca en niños o adolescentes, por las responsabilidades que implica. La normativa peruana es clara en determinar que los padres deben asumir el desarrollo integral de sus hijos ${ }^{13}$ y asimismo, otorga deberes en los niños y adolescentes, que aluden a que éstos deben brindar su colaboración en el hogar, que refiere fundamentalmente a tareas domésticas de menor importancia. ${ }^{14}$

\subsection{El niño como propiedad de los padres}

Esta representación social logra cosificar a los niños, para que sean vistos como objetos de propiedad de los padres. Sin embargo, la Convención sobre los Derechos del Niño y la normativa vigente de la especialidad, plantea que la autoridad de los padres en relación a sus hijos debe favorecer a la protección garantista, por entender que la finalidad de la patria potestad es favorecer al desarrollo integral de su prole; es un encargo social que los padres asumen, partiendo de la presunción que cumplirán sus responsabilidades en favor del niño.

Esta representación social favorece que los niños y adolescentes sean maltratados en su contexto familiar, en la medida que los padres se atribuyen la potestad de disciplinarlos según su propio parecer y que toda injerencia en su vida privada y familiar sería excesiva, arbitraria e ilegal ${ }^{15}$. Desconociendo que la normativa peruana ha sido explícita en establecer la prohibición de todo castigo corporal y trato humillante en perjuicio de $\operatorname{los}_{\text {hijos }}{ }^{16}$; de esta manera, ha sido limitada la autoridad parental.

Otra manifestación extrema es la utilización de niños como escudos humanos, sea para delinquir o para los padres evitar ser replegados por las autoridades en manifestaciones públicas. En relación al primero, solo con

\footnotetext{
Artículo II del Título Preliminar, 4 y 8 del Código de los Niños y Adolescentes

Artículo 8 y artículo 74 literal a) del Código de los Niños y Adolescentes.

Artículo 24 literal d) del Código de los Niños y Adolescentes.

Sobre el particular, en la Encuesta de Hogares del INEI del 2014 se recoge información en este sentido: un 19.8\% de las entrevistadas cree necesario castigar a sus hijos para educarlos. A ello se suma que el $28.6 \%$ de madres y el $25.6 \%$ de padres refieren que usan golpes para disciplinar a sus hijos, con más frecuencia en la selva.

16 Ley N³0403 del 30 de diciembre del 2015.
} 
el objetivo de ejemplificar reconocemos el caso del sujeto que ingresó con su pequeño de dos años y procedió a encañonar a la empleada de un grifo del distrito Carabayllo, despojándola del dinero. Esta escena fue presenciada por su otro hijo de cuatro años, tal y como consta en la grabación del 18 de octubre del $2015 .{ }^{17}$

En relación al segundo supuesto, podemos aludir a lo sucedido en mayo del 2007, en que se dio el desplazamiento de treintaicinco fiscales (penales, de familia y de prevención del delito) al mercado de Santa Anita, que buscó convencer a las mujeres a no exponer a sus hijos al momento de contrarrestar el desalojo, en la medida que se incurría en el delito de exposición de menores a peligro. ${ }^{18}$ Posteriormente, en julio del mismo año, miembros del Sindicato Unitario de Trabajadores en la Educación del Perú (SUTEP) se movilizaron por las calles de Puno, al lado de sus hijos y alumnos. ${ }^{19}$

Finalmente, otra visualización de los niños como propiedad de los padres, son los procesos de tenencia, en que los padres conciben que el niño le pertenece "como su propiedad" y que el otro progenitor ${ }^{20}$ no es merecedor de tenerlo consigo. Sobre el particular, la Convención sobre los Derechos del Niño, alude al derecho del niño al contacto con ambos padres y asimismo, la normativa nacional refiere que el juez debe priorizar otorgar la tenencia al padre/madre que garantice mejor el contacto del niño con el otro progenitor. Pero la máxima expresión de esta representación sucede en aquellos casos cuando los hijos son arrebatados de sus padres con violencia por parte del otro progenitor.

\subsection{El niño como estorbo}

Hasta la actualidad, los niños siguen siendo abandonados recién nacidos en las calles. Esto ha originado que se presente el Proyecto de Ley de "Cunas Salvadoras", aludiendo a incubadoras que serían acondicionadas en centros de salud, sean públicos o privados, o en entidades sin fines de lucro. Favoreciendo a que éstas puedan abandonar a sus hijos recién nacidos cuando no deseen criarlos. Se desconoce que esta estrategia es histórica, tal y como mencionáramos en el presente trabajo cuando aludimos a los tornos de los hospicios. El resultado fue cerrarlos porque promovieron el abandono de los hijos. En la actualidad, la temática está regulada como "niños en desprotección familiar" (o sin cuidado parental), buscando erradicar nominaciones peyorativas como "niños en estado de abandono", puesto que son personas y no cosas para ser abandonadas.

\footnotetext{
Ver: http://larepublica.pe/impresa/sociedad/711351-sujeto-armado-asalto-un-grifo-en-carabayllo-usando-su-hijo-como-escudo

Ver: Diario El Comercio, 18 de mayo del 2007, p.a2.

Ver: Diario El Comercio, 19 de julio del 2007, p.a2.

Artículo 84 del Código de los Niños y Adolescentes.
} 
Otras representaciones sociales no tratadas en este trabajo pero no menos importantes son: el niño como como objeto sexual, el niño como factor económico y el niño peligroso. Las cuales no deben considerarse como una lista taxativa sino más bien amplia que pueda favorecer a la denuncia de todas aquellas circunstancias o situaciones que evidencian una transgresión de derechos en los niños.

\subsection{El niño y adolescente como sujeto peligroso}

El adolescente que trasgrede la ley penal es visto en la actualidad como un "sujeto peligroso" para el orden social y la seguridad social. De esta manera, se han propuesto dos proyectos de ley: $N^{\circ} 1107 / 2011-C R$ y $N^{\circ}$ 1113/2011-CR.

En el primero, se propone modificar los artículos 20 y 22 del Código Penal. Que el artículo 20 indique: “Está exento de responsabilidad penal: 2). El menor de 18 años, salvo que haya incurrido en delito de Homicidio Calificado, Violación de la Libertad Sexual, u otro delito sancionado con pena privativa de la libertad no menor de veinticinco años o cadena perpetua, en cuya situación el Juez mediante Resolución debidamente motivada y revisada por el Superior, dispondrá su juzgamiento y/o sanción como mayor". Mientras que en el segundo proyecto se busca modificar el artículo 20 numeral 2) del Código Penal y en consecuencia, reducir la edad de imputabilidad de 18 a 16 años ante la comisión de ciertos delitos considerados graves (asesinato, lesiones graves, secuestro, trata de personas, robo agravado, extorsión, asociación ilícita, entre otros).

En ambos proyectos, se desconoce totalmente la condición de sujeto en desarrollo del adolescente y por lo tanto, no merecedor por el principio de igualdad, del mismo trato penal que corresponde a un adulto. Las representaciones sociales que enmarcan estas propuestas son: "como adulto" y "como sujeto peligroso". En contraposición a miradas punitivas, retributivas y sin ningún sustento en evidencias, se proponen tratamientos diferenciados en base a los perfiles existentes de adolescentes en conflicto con la ley penal, cuestión plenamente respaldada por el próximo Código de Responsabilidad Penal, que próximamente entrará en vigencia.

\section{CONCLUSIONES}

1. Las representaciones sociales que reflejan la invisibilidad del niño como un sujeto de derechos en formación y desarrollo no permiten la vigencia de sus derechos en los entornos en que se desenvuelven. 
2. Las representaciones sociales por tratarse de una cuestión cultural, permanecen arraigadas y son difíciles de erradicar; asimismo, pueden reflejarse más de una representación social en los hechos denunciables de agravio de los derechos de los niños o adolescentes.

3. En la historia de las representaciones sociales de la infancia se puede identificar como su invisibilidad en el ámbito social favoreció la inexistencia de instituciones que le prodigarán protección y trato diferenciado en relación a los adultos, especialmente en el ámbito penal.

4. La Convención sobre los Derechos del Niño, forjada como normativa de obligatorio cumplimiento en la sociedad peruana desde 1990, busca generar una nueva representación social de los niños en base a su consideración como sujeto de derechos, deberes y obligaciones, cuyo ejercicio y exigibilidad va aparejada de su edad y madurez.

\section{REFERENCIAS}

Ariès, Philippe (1973). El niño y la vida familiar en el Antiguo Régimen. Madrid, España: Edit. Taurus.

Ballón, Ildefonso (1935). Anteproyecto presentado a la Comisión encargada del Proyecto del Código de Menores. Lima, Perú.

Bullrich, Eduardo (1919). Asistencia Social de Menores. Buenos Aires, Argentina: Jesús Menéndez Librero Editor.

Bustos Ramírez, Juan (1992). Un Derecho Penal del Menor. Santiago de Chile, Chile: Ed. Jurídica Cono Sur.

Bustos Ramírez, Juan (2004). Obras Completas.Control social y otros estudios. Tomo II. Lima, Perú: Ara Editores EIRL.

Castillo Ríos, Carlos (1968). Derecho de Menores. Consejo Nacional de Menores. Lima, Perú.

Donzelot, Jacques (sin fecha). La Conservación de los hijos. Recuperado de : http://www.iin.oea.org/Cursos_a_distancia/la_conservacion_de_los_ hijos.pdf

García Méndez, Emilio (1997). "Prehistoria e Historia del Control Sociopenal de la Infancia: Política Jurídica y Derechos Humanos en 
América Latina". Materiales de lectura Post-Título "Justicia, Derechos y Politicas Públicas para la Infancia y Adolescencia" . Santiago de Chile, Chile : Universidad Diego Portales.

García Méndez, Emilio (sin fecha). Legislaciones Infanto-Juveniles en América Latina: Modelos y Tendencias. p.17.

García Méndez, Emilio (sin fecha). Para una historia del control penal de la infancia: La formalidad de los mecanismos formales de control social. Op cit p. 164.

Mateo de Ferroni, Delia(2000). Régimen Penal de Menores. Santa Fe de Bogotá, Colombia: Editorial Juris.

Morales Georgina (2001). La Divergencia ente la Ley Tutelar de Menores y la Convención sobre los Derechos del Niño. Caracas, Venezuela: Universidad Central de Venezuela.

Palomba, Federico (1995). Tendencias Evolutivas en la protección de los menores de edad. La niñez y adolescencia en conflicto con la ley penal. San Salvador, El Salvador: Editorial Hombres del Maiz.

Panez, Rosario (1989). Bajo el Sol de la Infancia: creencias y tradiciones en la crianza limeña. Lima, Perú : CONCYTEC

Tur, Cristina(active 22,2010) La historia de Mary Ellen . Recuperado de: http: / / territoriocat.wordpress.com/2010/10/22/la-historia-de-maryellen/

Comisión de la Verdad y Reconciliación(sin fecha)Explicando el conflicto armado interno. Recuperado de :

http:/ / www.usip.org/sites/default/files/file/resources/collections/ commissions/Peru01-Report/Peru01-Report_Vol8.pdf

Inforegión (22 de febrero de 2010). Sendero Luminoso estaría formando nuevos comites populares en Ayacucho y VRAE. Recuperado de:

http: / / www.inforegion.pe/49653/ sendero-luminoso-estaria-formandonuevos-comités-populares-en-ayacucho-y-el-vrae/

Ley N³0403. Diario Oficial El Peruano, Lima, Perú, 30 de diciembre del 2015.

Gamboa, Edgar (18 de Octubre de 2015). Sujeto Armado asaltó un grifo en Carabayllo usando su hijo como escudo. Sociedad. Recuperado de :

http: / / larepublica.pe/impresa / sociedad / 711351-sujeto-armado-asaltoun-grifo-en-carabayllo-usando-su-hijo-como-escudo 
Ley $\mathrm{N}^{\circ}$ 27337. Ley que aprueba el nuevo Código de lo Niños y Adolescentes. Congreso de la República del Perú, Lima, 21 de Julio de 2000.

Fecha de recepción: 31 de agosto de 2017

Fecha de aceptación: 13 de setiembre de 2017 